ACCEPTED MANUSCRIPT

\title{
Photothermal lysis of Pseudomonas aeruginosa by polyaniline nanoparticles under near infrared irradiation
}

To cite this article before publication: Silvestre Bongiovanni Abel et al 2018 Biomed. Phys. Eng. Express in press https://doi.org/10.1088/20571976/aacf33

\author{
Manuscript version: Accepted Manuscript \\ Accepted Manuscript is "the version of the article accepted for publication including all changes made as a result of the peer review process, \\ and which may also include the addition to the article by IOP Publishing of a header, an article ID, a cover sheet and/or an 'Accepted \\ Manuscript' watermark, but excluding any other editing, typesetting or other changes made by IOP Publishing and/or its licensors" \\ This Accepted Manuscript is @ 2018 IOP Publishing Ltd.
}

During the embargo period (the 12 month period from the publication of the Version of Record of this article), the Accepted Manuscript is fully protected by copyright and cannot be reused or reposted elsewhere.

As the Version of Record of this article is going to be / has been published on a subscription basis, this Accepted Manuscript is available for reuse under a CC BY-NC-ND 3.0 licence after the 12 month embargo period.

After the embargo period, everyone is permitted to use copy and redistribute this article for non-commercial purposes only, provided that they adhere to all the terms of the licence https://creativecommons.org/licences/by-nc-nd/3.0

Although reasonable endeavours have been taken to obtain all necessary permissions from third parties to include their copyrighted content within this article, their full citation and copyright line may not be present in this Accepted Manuscript version. Before using any content from this article, please refer to the Version of Record on IOPscience once published for full citation and copyright details, as permissions will likely be required. All third party content is fully copyright protected, unless specifically stated otherwise in the figure caption in the Version of Record.

View the article online for updates and enhancements. 


\section{Photothermal lysis of Pseudomonas aeruginosa by polyaniline nanoparticles under Near Infrared Irradiation}

Silvestre Bongiovanni Abel ${ }^{\mathrm{a}}$, Lucas A. Gallarato ${ }^{\mathrm{b}}$, Marta S. Dardanelli ${ }^{\mathrm{b}}$, César A. Barbero ${ }^{\mathrm{a} *}$, Claudia R. Rivarola ${ }^{\text {, and Edith }}$ I. Yslas ${ }^{\mathrm{b} *}$.

${ }^{a}$ Instituto de Investigaciones en Tecnologías Energéticas y Materiales Avanzados (IITEMA), Univerșidad Nacional de Río Cuarto (UNRC)- Consejo Nacional de Investigaciones Científicas y Técnicas (CONICET). Ruta Nacional No 36, Km 601, Agencia Postal No 3, 5800, Río Cuarto, Argentina.

${ }^{\mathrm{b}}$ Departamento de Biología Molecular, Consejo Nacional de Investigaciones Científicas y Técnicas (CONICET), Facultad de Ciencias Exactas, Fisicoquímicas y Naturales, Universidad Nacional de Río Cuarto, Ruta 36 Km 601, 5800, Río Cuarto, Argentina.

*Corresponding authors

Dra. Edith I. Yslas, email: eyslas@exa.unrc.edu.ar

Dr. César Barbero, email: cbarbero@exa.unrc.edu.ar 


\begin{abstract}
Increases in the prevalence of antibiotic resistant bacteria require new approaches for the treatment of infectious bacterial pathogens. A new therapeutic modality, which is called photothermal therapy (PTT) involves the absorption of Near Infrared Radiation (NIR) light by absorbing species (e.g. polyaniline nanoparticles) and transfer of the absorbed energy into the surrounding environment as heat that could cause pathogen death. Since the pathogen cells, and the surrounding tissue, does not absorb NIR radiation, an agent which strongly absorb the light has to be added. In this work, were performed experiments to determine if polyaniline nanoparticles (PANI-NP) in combination with NIR irradiation could be used to destroy Pseudomonas aeruginosa. Results reveal that this nanomaterial, following NIR exposure could be used for killing bacteria because it was observed a significant decrease in cell viability triggering cell death. In addition, the cell death mechanism was observed by DNA fragmentation.
\end{abstract}

Keywords: Nanomaterials - Polyaniline Nanoparticles - Photothermal Therapy - Pathogenic bacteria - Bacterial death

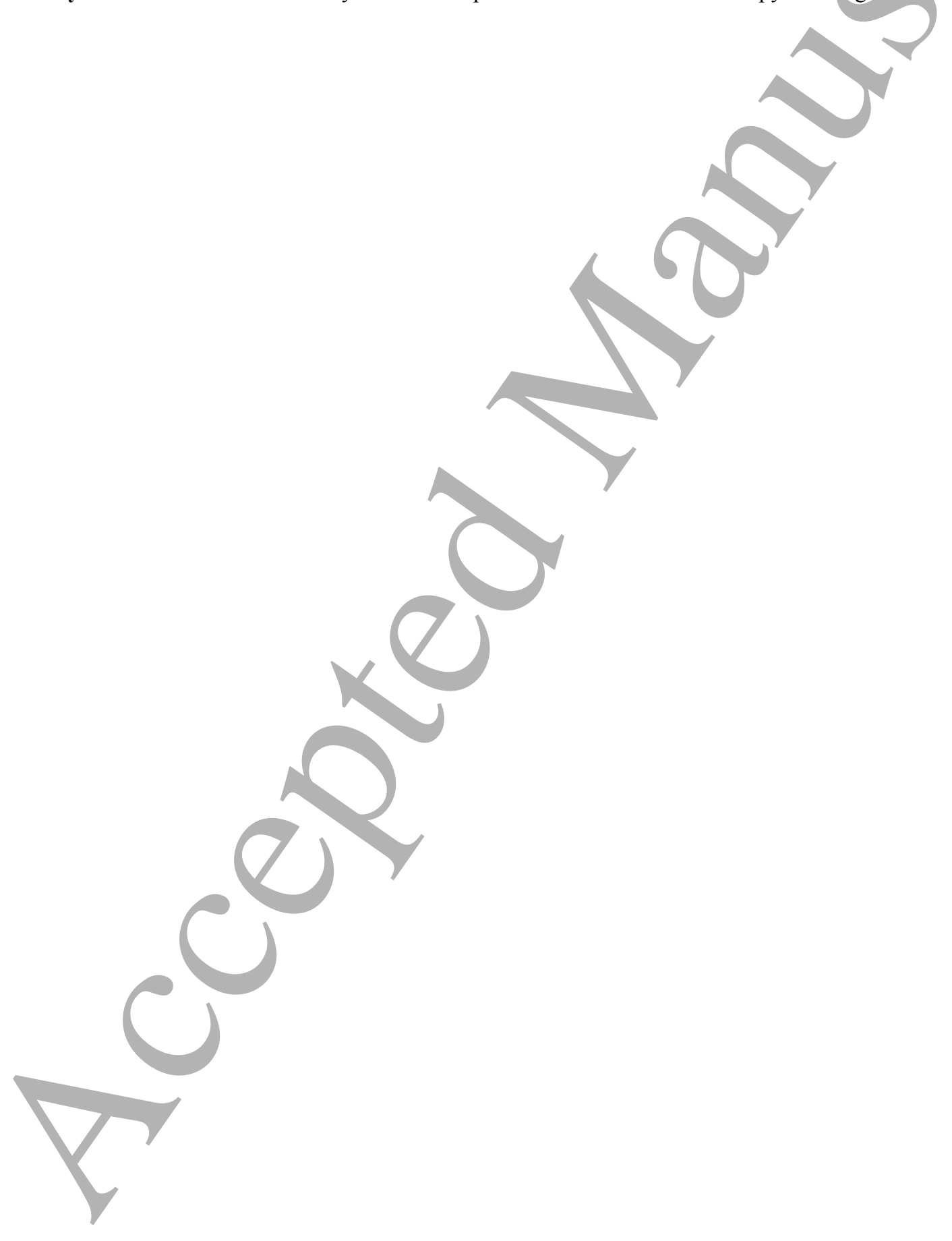




\section{Introduction}

Conventional antibiotic therapy, play critical roles in treating pathogenic infections caused by bacteria which have been used for decades. However, the use of antibiotics, leads to the rise of drug resistance. The multidrugresistant (MDR) is becoming an increasingly urgent worldwide health problem. Therefore, there is an urgent need for the development new antibacterial materials or effective therapeutic modalities to resolve this emerging problem. One of the most common causes of infections in nosocomial ambient and community in general is Pseudomonas aeruginosa, a flagellate bacterium with rod-like shape. This microorganism is classified as a Gramnegative that has the capacity to easily adapt to distinct environments such as soil, marshes, plants and animal tissues ${ }^{1,2}$. This bacterium can achieve high cell contaminations which remain stable for long periods of time ${ }^{3}$. $P$. aeruginosa is an opportunistic pathogen causing a wide range of systemic or local infections and that could be cause numerous problems, mainly in patients suffering from predisposing conditions such as cystic fibrosis, burn wounds and immunodeficiency ${ }^{4}$. Nowadays, some microorganism among $P$. aeruginosa became resistant to various drugs (e.g. antibiotics) affecting the treatment of nosocomial infections ${ }^{5,6}$. The increasing occurrence of MDR strains among pathogen microbes has become one of most important problems in medicine worldwide. It is therefore that the prevention of infections caused by these pathogens and new therapeutic modalities are urgently needed ${ }^{7}$.

Photothermal therapy (PTT) is an attractive therapeutic technique and a kind of photo-assisted therapy where the Near Infrared Radiation (NIR) -range between $700-1200 \mathrm{~nm}$ - is used in combination with a nanomaterial which absorbs the light to generate localized heat ${ }^{8}$. Owing to the fact that in that wavelength range (NIR), biological tissues and water -the main component of live systems- are transparent, a window for therapeutic applications is emerging ${ }^{9}$. Heat generation, also called hyperthermia, is able to produce pathogen death. With this objective, different materials were reported as photothermal agents: magnetic materials, ${ }^{10,}{ }^{11}$ gold, silver, and paladium nanoparticles, ${ }^{12-14}$ carbon based materials (e.g. graphene oxide, nanotubes, etc) ${ }^{15-19}$ and conducting polymers (e.g. polyaniline, polypyrrole, and others) in several forms ${ }^{20-23}$.

One of the most interesting conducting polymers that can be used to generate different forms of nanomaterials to apply in biological systems is polyaniline ${ }^{24,25}$. Thin films, nanofibers and nanoparticles are some of these forms useful to study the effect of PTT on living organism ${ }^{26,27}$. Polyaniline nanoparticles (PANI-NP) can be used as a photothermal agent ${ }^{28}$. In this context, in our laboratory, the mentioned nanomaterials were used to in vitro and in vivo hyperthermia generation assays ${ }^{29,30}$. Besides, ecotoxicology experiments using an animal model of amphibious were made: acute - short term chronic toxicity and teratogenic properties was evaluated with acceptable and desirable results ${ }^{31,32}$. However, PTT using this material has only been tried as antitumoral therapy. Since it is well known ${ }^{33}$, that tumor cells are less resistant to a temperature increase than normal cells, PTT is highly effect. We recently tried PTT Even though the therapy was effective, it is possible for the organic solvent used in the synthesis (N-methylpyrrolidone against Pseudomonas aeruginosa with another kind of nanoparticles (generated by solvent displacement method) ${ }^{34}$., NMP) to decrease in cell viability. In the current work, we propose PANI-NP synthesized in aqueous media (NMP free) as agent in PTT as antibacterial nanotherapy where no NMP effect is present. The aim of this study is evaluate the capacity of PANI-NP as photothermal agent in the treatment of pathogenic bacteria such as Pseudomonas aeruginosa. After the synthesis of the nanomaterial and physicochemical characterization, experiments related with the in vitro photothermal effect were made. Irradiation with NIR light in this kind of bacteria was tested with excellent results. Besides, DNA fragmentation was observed indicating that the combination of PANI-NP with NIR light is capable of generating DNA damage on the pathogenic bacteria.

\section{Materials and Methods}

\subsection{Chemical reagents}

Hydrochloride anilinium (ANI) used as monomer was obtained from Merck. Ammonium peroxydisulfate (oxidant) was purchased from S. Aldrich. Polyvinylpyrrolidone (Fluka, Mw= 360.000) were used as stabilizer 
agent of nanoparticles to avoid the agglomeration. Milli-Q quality water was used for all solutions and preparations. Other chemical were analytical reagents and used as received.

\subsection{Bacterial culture and preparation}

$P$. aeruginosa ATCC 15692 (PAO1 strain) were maintained at the temperature of $-80^{\circ} \mathrm{C}$ in glycerol stock solution. Bacteria cells were cultured at $37{ }^{\circ} \mathrm{C}$ in an aerobic atmosphere and then transferred to LB plates (LuriaBertani broth). Cultures grown overnight in LB nutrient medium and were harvested at the exponential growth phase. The cells were finally resuspended in sterile saline solution $(0.85 \% \mathrm{NaCl})$.

\subsection{Light source (PTT)}

The Photothermal Therapy (PTT) experiment was carried out using a Near-Infrared (NIR) laser at a wavelength emission of $785 \mathrm{~nm}$ and $500 \mathrm{~mW}$ power. The temperature was recorded by a TES $1326 \mathrm{~S} / 1327 \mathrm{~K}$ infrared thermometer and /or by a $\mathrm{K}$ type thermocouple.

\subsection{Nanoparticles Synthesis}

In order to obtain PANI-NP, a $0.2 \mathrm{M}$ solution of aniline hydrochloride was mixed with a $0.25 \mathrm{M}$ solution of the oxidant (APS) in the presence of the stabilizer (PVP, $2 \mathrm{w} / \mathrm{w} \%$ ). Polymerization was carried out at room temperature $\left(20 \pm 0.1^{\circ} \mathrm{C}\right)$ under stirring for 30 minutes. When a dark-green dispersion was obtained, synthesis was considered by finalized ${ }^{24,35}$. In Scheme 1, the reaction to produce PANI-NP is represented. Note that the resulting polymer after oxidative reaction is PANI. PVP is the stabilizer that interacts with the water due to its hydrophilic characteristics and stabilize the colloidal dispersion.

\subsection{Physical-chemical characterization}

Dynamic Light Scattering (DLS) technique, SEM and TEM microscopic and UV-Visible measurements were used to characterize PANI-NP dispersion. For DLS studies, a Malvern 4700 DLS device was employed. Measurements were made using the conditions that are bellow detailed: $\mathrm{pH}=3.5$ (resulting after synthetic process), $25^{\circ} \mathrm{C}$ and scattering angle of $90^{\circ}$. Respect Scanning Electron Micrographs, a Carl Zeiss (EVOMA10) microscope at low vacuum and low field was used. Transmission electron microscopy (TEM) was performed with a JEOL JEM-1010 microscope. PANI-NP dispersion was deposited on a copper grid. UV-Visible spectroscopy was measured in a Hewlett-Packard 8453 diode array UV-Visible spectrophotometer using quartz cells of $1 \mathrm{~cm}$ path length. FT-IR spectrum was taken using a Bruker Tensor 27 Spectrometer with the nanoparticles contained in $\mathrm{KBr}$ pellets.

\subsection{Antibacterial activity}

Gram-negative $P$. aeruginosa were grown in $25 \mathrm{~mL} \mathrm{LB}$ broth overnight aerobically in sterile condition at 37 ${ }^{\circ} \mathrm{C}$ with shaking. An aliquot of the bacterial culture was transferred fresh LB broth and incubated at $37{ }^{\circ} \mathrm{C}$ to exponential phase of growth. After, bacterial concentration of the suspension was checked, resulting $10^{6}$ cells in saline solution. Then, the nanomaterials were added into bacterial suspensions. The concentrations of PANI-NP were $0.404 \mathrm{mg} / \mathrm{mL}, 0.606 \mathrm{mg} / \mathrm{mL}, 0.830 \mathrm{mg} / \mathrm{mL}$, and $1.404 \mathrm{mg} / \mathrm{mL}$. Incubation was carried out at $37^{\circ} \mathrm{C}$ during 3 hours with $P$. aeruginosa cells (CFU $\left.10^{6} / \mathrm{ml}\right)$ in saline solution in contact with the nanomaterial. A bactericidal effect was defined as a decrease in CFU/ml after 24 hours. In these assay, controls used were the following: cells in isotonic saline solution $(0.85 \% \mathrm{NaCl})$ without nanoparticles as positive control group, $\mathrm{LB}$ medium as negative control. Experiments were prepared in triplicate and performed independently three times.

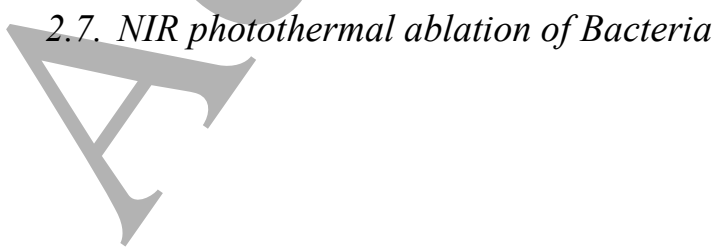




\subsection{DNA fragmentation}

Firstly, bacteria were incubated with PANI-NP in a concentration of $0.404 \mathrm{mg} / \mathrm{L}$. DNA was extracted after 5 hours of incubation post-irradiation according to the protocol descripted by Kumar et al. ${ }^{36}$ Then, fragmentation was tested using the DNA ladder assay. Electrophoresis of the extracted DNA was carried out on a $0.8 \%$ agarose gel, staining with gel green to allow the DNA visualization.

\subsection{Statistical analysis}

The results were analyzed by one way analysis of variance (ANOVA) and Tukey test. Statistical significance were defined as ${ }^{*} \mathrm{p}<0.05$ and ${ }^{* *} \mathrm{p}<0.01$. Data were represented as the mean \pm standard deviation of each group.

\section{Results and discussion}

\subsection{Nanoparticles characterization}

PANI-NP was obtained, after the synthetic process detailed in experimental section (2.4), as a dark-green dispersion at $\mathrm{pH}=3.5$. Dynamic Light Scattering measurement (Figure 1) reveals that nanoparticles are monodisperse at room temperature $\left(25 \pm 0.1^{\circ} \mathrm{C}\right)$. By the mentioned technique, a Gaussian normal distribution of size was obtained. Average size (hydrodynamic diameter) was estimated in $220 \pm 5 \mathrm{~nm}$ and Polydispersity Index (P.D.I.) result 0.145 . Besides, zeta potential measurements of the obtained dispersion reveal that particles have neutral surface charge $(-7.58 \mathrm{mV})$. After that, electronic microscopies of the dispersion were taken out. In Figure 2, images of SEM, TEM, and AFM experiments are shown. Spherical particles are observed. The SEM images showed a homogeneous size distribution with an average size $\bar{x}=177.96 \mathrm{~nm} \pm \mathrm{SD}=13.26 \mathrm{~nm}$. The sizes of the nanoparticles by TEM were with an average size $\bar{x}=145.38 \mathrm{~nm} \pm \mathrm{SD}=12.53 \mathrm{~nm}$. However, note that the size appreciated can be also less than DLS measurement $(<200 \mathrm{~nm})$. The difference could be attributed to the lack of the hydration layer due to in the first technique the estimation was based on Stokes-Einstein behavior and micrographs was taken in dry state ${ }^{31}$. To ascertain the chemical structure of the nanoparticles, a FT-IR spectrum was taken (Figure 1, SI). The spectrum of the conducting polymer in nanoparticles is similar to those reported for PANI bulk and nanoparticles generated by other methods ${ }^{34,37,38}$. In this sense, it is likely that the stabilizer agent (PVP) is only absorbed on the surface of the conducting polymer interacting with the aqueous medium to avoid 
the precipitation (non-covalent bind). Also, it is important remark that PANI-NP are stable for several months and could be redispersed in water.

Spectroscopic measurement show that nanoparticles absorb in the near infrared range of the spectra. As can be seen in Figure 3, in acidic media $(\mathrm{pH}=3.5)$, PANI-NP presents three definite bands. The band at 300 c.a. is due to the $\pi \rightarrow \pi^{*}$ transition of the PANI aromatic rings. In $420 \mathrm{c}$.a. is possible appreciate the band corresponding to the formation of a doping level owing to "exciton" transition $\left(n \rightarrow \pi^{*}\right)$. The spectrum is in agreement with previous research in bulk polyaniline material and other PANI nanostructures ${ }^{24,25,29,39-41}$. For NIR PTT applications the most important band in the PANI-NP UV-Visible spectra is the one that appears at ca. $700 \mathrm{~nm} / \mathrm{which}$ is assigned to the polaron absorption of PANI (related with quinonimine states). In this context, is possible assume that the nanomaterial is into the therapeutic window ${ }^{42,43}$. In our previous reports ${ }^{29}, 30$, we try photothermal therapy on cancer cells with PANI-NP, reading a temperature change $(\Delta \mathrm{T})$ of $12{ }^{\circ} \mathrm{C}$. However, in the best of our knowledge, no evaluation of this nanomaterial (free of organic solvent) as photothermal agent in this kind of pathogenic bacteria has been reported.

\subsection{Antibacterial activity of PANI-NP}

Some authors reported antibacterial effect of materials based on PANI. In most of them, researchers used the conducting polymer combined with other materials such as silver ${ }^{44}$, nickel-iron ${ }^{45}$, platinum-palladium ${ }^{46}$, gold ${ }^{47}$ or antibacterial drugs ${ }^{48}$ in several forms (films, surfaces or composites) $23,45,49,50$.

On the other hand, the aim of the present work is to assess the antibacterial activity of PANI-NP without any component or functionalization under NIR irradiation. First, after exposition of P. aeruginosa to the nanomaterial, the antibacterial capability of PANI-NP was studied without the assistance of NIR. Four different concentrations of the polymeric nanoparticles were tried and compared to the control (absence of nanoparticles). The viabilities of bacteria were studied by using a plate-counting method. The results obtained are shown in Figure 4. Control was able to produce a growth of approx. $10 \times 10^{8} \mathrm{CFU} / \mathrm{mL}$. However, when pathogenic bacteria were exposure to PANI-NP, a bactericidal effect was observed in a concentration dependent manner. Concentration of nanomaterial is a very important factor to be considered: as the concentration increases, the effect is more remarkable. At concentration of $0.404 \mathrm{mg} / \mathrm{mL}$ of the PANI-NP, CFU decreases to $9.61 \times 10^{8} \mathrm{CFU} / \mathrm{mL}$. If the concentration increases to $0.606 \mathrm{mg} / \mathrm{mL}$, the result obtained is less than $8 \times 10^{8} \mathrm{CFU} / \mathrm{mL}$. However, it is possible improve the bactericidal effect at 0.830 and $1.04 \mathrm{mg} / \mathrm{mL}$ of PANI-NP, $6.65 \times 10^{8} \mathrm{CFU} / \mathrm{mL}$ and $5.16 \times 10^{8} \mathrm{CFU} / \mathrm{mL}$, respectively. In this form, we demonstrate that polyaniline nanoparticles are able to generate the growth inhibition without the use of any light source in the case of Pseudomonas aeruginosa.

\subsection{NIR photohermal killing of bacteria}

In the previous section, the antibacterial activity of PANI-NP alone on P. aeruginosa was shown. Then, we study the combined action of PANI-NP with the NIR light (PTT). Figure 5, shows the viability percentage of bacteria after photothermal therapy, in presence of PANI-NP, compared with light control (NIR irradiation alone). The bacterial survival rate was still around $100 \%$ after NIR irradiation for 15 min, meaning that NIR irradiation alone was harmless to bacterial strain respect the control. Besides, the contact of PANI-NP with the bacteria neither affect the number of live microorganism. This revealed that the growth of bacteria was not significantly affected by PANI-NP or irradiated only, due that no significant reduction of colonies was seen. However, the combination of the nanomaterial and NIR exposition reduce de viability of pathogenic bacteria in ca. $80 \%$ with respect the initial population. The viabilities of the bacterial groups treated with PANI-NP and irradiated were remarkably decreased compared with those in other groups. This fact demonstrate that PANI-NP is an effective photothermal agent to inhibit the grown of P. aeruginosa. 


\section{Conclusions}

In conclusion, we demonstrate in this work that PANI-NP has a new application in the field of photothermal therapy that is the killing of pathogenic bacteria. PANI nanoparticles were synthesized by in-situ polymerization and characterized using spectroscopic, microscopic and light dispersion techniques. This is the first time that the effect of the polymeric nature of this nanomaterial (free of NMP) combined with the NIR irradiation was evaluated to kill P. aeruginosa. The PTT treatment induces death of more than $80 \%$ of the pathogenic bacteria. We confirmed the affectivity of the treatment with complementary techniques such as fluorescence microscopy and DNA fragmentation assays, obtaining evidence of the DNA damage in P. aeruginosa cells. Results showed that the combination of PANI-NP and irradiation severely damage the membrane, which caused loss of the cell membrane integrity. Then, this resulted in the DNA damage, and finally cell death. We can conclude that this method of photoelimination by PTT could significantly reduce the load of $P$. aeruginosa. Therefore, our obtained data highlighted the potential of using PANI-NP such as photothermal agent and as a potential photothermal antimicrobial nanotherapy.

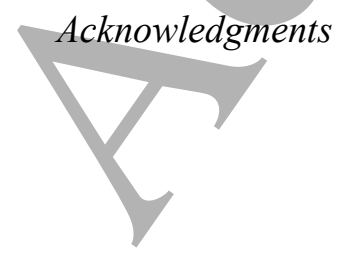

Photothermal conversion efficiency ( $\eta$ ) is an important parameter to quantify the effect of PANI-NP. An interesting method to estimate the parameter was reported by $\mathrm{Hu}$ et al. in the last years ${ }^{51}$. Using the mentioned method, we calculated the photothermal conversion efficiency of our material, resulting $\eta=28.16 \%$. The result reveals that PANI-NP presents a considerable PTT effect and it is comparable with other materials such as

In order to reach a better understanding of the mentioned phenomena, fluorescence microscopy was applied to asses live and dead cells. Figure 6 allow to observe the response to a Live/Dead viability kit. For differentiation of live/dead microbial cells, two stains were used: SYTO ${ }^{\circledR} 9$ and Propidium Iodide (PI). SYTO ${ }^{\circledR} 9$ penetrates all bacterial membranes (intact and injured) and labels bacterial cells green. Propidium Iodide can only penetrate staining with propidium iodide can be seen, which follows treatment with PANI-NP and NIR irradiation (wavelength of $785 \mathrm{~nm}$ of $500 \mathrm{~mW} . \mathrm{cm}^{-2}$ ) wich indicate disruption of cell walls of the bacterium resulting in death. It is clear, that only the combination of the nanoparticles at concentration of $0.404 \mathrm{mg} / \mathrm{ml}$ of PANI-NP with the
NIR light is capable to kill the bacteria. Under NIR irradiation, the PANI-NP exhibited the highest efficiency in photothermal lysis of gram-negative bacteria. In (a), (b) and (c), P. aeruginosa remain viable/live cells in green. Finally, the bacteria incubated with PANI-NP and irradiated with NIR light could efficiently absorbed this
irradiation and convert it into heat, increasing the local temperature to kill the bacteria. The radical importance of this behavior is the capacity of the nanomaterial to convert the radiation from the light in localized heat by perthermia mechanism. Although in previous works the photothermal effect of nanoparticles was demonstrated, this is the first report showing that this mechanism can be used to kill pathogenic bacteria. These results are
important for us because now we found a new approach for PANI-NP that is added to the other applications that we found in previous research related with the photothermal effect of this material ${ }^{24,29,30}$.

In addition, mechanism of cell death was studied by electrophoretic DNA fragmentation. Experiments were take considering the four conditions described control ( $P$. aeruginosa), bacteria incubated with PANI-NP, microorganism exposed to NIR light and the combination of radiation and nanomaterial. In Figure 7, a
photographic image of the electrophoretic run is shown. As it can be seen, in comparison with the controls, when both PANI-NP and NIR light is present a clear DNA damage is observed. The results are in agreement with the cell death experiment showed in the previous section. It is clear that PTT plays an important role to produce this damage in the DNA of the pathogenic bacteria since exposure to the nanomaterial alone is not able to generate the mentioned damage.

$$
\text { antimicrobial nanotherapy. }
$$


This work was supported by grants from Consejo Nacional de Investigaciones Científicas y Técnicas (CONICET), Agencia Nacional de Promoción Científica y Tecnológica (PICT 2016-0417), Secretaría de Ciencia y Técnica (SECyT), Universidad Nacional de Río Cuarto, Argentina. S. Bongiovanni Abel thanks CONICET for graduate research fellowship. M. Dardanelli, C. Barbero, C .R. Rivarola and E. I. Yslas are permanent research members of CONICET.

\section{References}

1. Teixeira, P.; Tacão, M.; Alves, A.; Henriques, I. Marine Pollution Bulletin 2016, 110, (1), 75-81.

2. Madigan, M. T.; Clark, D. P.; Stahl, D.; Martinko, J. M., Brock Biology of Microorganisms 13th edition. Benjamin Cummings: 2010.

3. Favero, M.; Carson, L.; Bond, W.; Petersen, N. Science 1971, 173, (3999), 836-838.

4. Zhao, W.-H.; Hu, Z.-Q. Critical reviews in microbiology 2010, 36, (3), 245-258.

5. Jansen, K. U.; Girgenti, D. Q.; Scully, I. L.; Anderson, A. S. Vaccine 2013, 31, (25), 2723-2730.

6. Marta, B.; Jakab, E.; Potara, M.; Simon, T.; Imre-Lucaci, F.; Barbu-Tudoran, L.; Popescu, O.; Astilean, S. Colloids and Surfaces A: Physicochemical and Engineering Aspects 2014, 441, 77-83.

7. Wertheim, H. F.; Melles, D. C.; Vos, M. C.; van Leeuwen, W.; van Belkum, A.; Verbrugh, H. A.; Nouwen, J. L. The Lancet infectious diseases 2005, 5, (12), 751-762.

8. Huang, X.; El-Sayed, I. H.; Qian, W.; El-Sayed, M. A. Journal of the American Chemical Society 2006, $128,(6), 2115-2120$.

9. O'Neal, D. P.; Hirsch, L. R.; Halas, N. J.; Payne, J. D.; West, J. L. Cancer letters 2004, 209, (2), 171-176.

10. Huang, W. C.; Tsai, P. J.; Chen, Y. C. Small 2009, 5, (1), 51-56.

11. Hergt, R.; Dutz, S.; Müller, R.; Zeisberger, M. Journal of Physics: Condensed Matter 2006, 18, (38), S2919.

12. Dickerson, E. B.; Dreaden, E. C.; Huang, X.; El-Sayed, I. H.; Chu, H.; Pushpanketh, S.; McDonald, J. F.; El-Sayed, M. A. Cancer letters 2008, 269, (1), 57-66.

13. Castillo-Martínez, J. C.; Martínez-Castañón, G. A.; Martínez-Gutierrez, F.; Zavala-Alonso, N. V.; PatiñoMarín, N.; Niño-Martinez, N.; Zaragoza-Magaña, V.; Cabral-Romero, C. Journal of Nanomaterials 2015, $16,(1), 177$.

14. Xiao, J.-W.; Fan, S.-X.; Wang, F.; Sun, L.-D.; Zheng, X.-Y.; Yan, C.-H. Nanoscale 2014, 6, (8), 43454351.

15. Gurunathan, S.; Han, J. W.; Dayem, A. A.; Eppakayala, V.; Kim, J.-H. International journal of nanomedicine 2012, 7, 5901.

16. Moon, H. K.; Lee, S. H.; Choi, H. C. ACS nano 2009, 3, (11), 3707-3713.

17. Virani, N. A.; Davis, C.; MeKernan, P.; Hauser, P.; Hurst, R. E.; Slaton, J.; Silvy, R. P.; Resasco, D. E.; Harrison, R. G. Nanotechnology 2017, 29, (3), 035101.

18. $\quad \mathrm{Hu}$, Z.; Zhao, F.; Wang, Y.; Huang, Y.; Chen, L.; Li, N.; Li, J.; Li, Z.; Yi, G. Chemical Communications 2014, 50, (74), 10815-10818.

19. Hu, Z.; Wang, C.; Zhao, F.; Xu, X.; Wang, S.; Yu, L.; Zhang, D.; Huang, Y. Nanoscale 2017, 9, (25), 8825-8833.

20. Jiang, B.-P.; Zhang, L.; Zhu, Y.; Shen, X.-C.; Ji, S.-C.; Tan, X.-Y.; Cheng, L.; Liang, H. Journal of Materials Chemistry B 2015, 3, (18), 3767-3776.

21. Chen, M.; Fang, X.; Tang, S.; Zheng, N. Chemical communications 2012, 48, (71), 8934-8936.

22. Shao, Q.; Hu, Z.; Xu, X.; Yu, L.; Zhang, D.; Huang, Y. Applied Surface Science 2018, 440, 1159-1165.

23. $\mathrm{Hu}, \mathrm{Z}$; Shao, Q.; Huang, Y.; Yu, L.; Zhang, D.; Xu, X.; Lin, J.; Liu, H.; Guo, Z. Nanotechnology 2018, $29,(18), 185602$.

24. Abel, S. B.; Molina, M. A.; Rivarola, C. R.; Kogan, M. J.; Barbero, C. A. Nanotechnology 2014, 25, (49), 495602.

25. Yslas, E. I.; Ibarra, L. E.; Peralta, D. O.; Barbero, C. A.; Rivarola, V. A.; Bertuzzi, M. L. Chemosphere 2012, 87, (11), 1374-1380.

26. Humpolicek, P.; Kasparkova, V.; Saha, P.; Stejskal, J. Synthetic Metals 2012, 162, (7), 722-727. 
27. Stejskal, J.; Hajná, M.; Kašpárková, V.; Humpolíček, P.; Zhigunov, A.; Trchová, M. Synthetic Metals 2014, 195, 286-293.

28. Neira-Carrillo, A.; Yslas, E.; Marini, Y. A.; Vásquez-Quitral, P.; Sánchez, M.; Riveros, A.; Yáñez, D.; Cavallo, P.; Kogan, M. J.; Acevedo, D. Colloids and Surfaces B: Biointerfaces 2016, 145, 634-642.

29. Yslas, E. I.; Ibarra, L. E.; Molina, M. A.; Rivarola, C.; Barbero, C. A.; Bertuzzi, M. L.; Rivarola, V. A. Journal of Nanoparticle Research 2015, 17, (10), 1-15.

30. Ibarra, L.; Yslas, E.; Molina, M.; Rivarola, C.; Romanini, S.; Barbero, C.; Rivarola, V.; Bertuzzi, M. Laser Physics 2013, 23, (6), 066004.

31. Ibarra, L. E.; Tarres, L.; Bongiovanni, S.; Barbero, C. A.; Kogan, M. J.; Rivarola, V. A.; Bertuzzi, M. L.; Yslas, E. I. Ecotoxicology and environmental safety 2015, 114, 84-92.

32. Ibarra, L. E.; Bongiovanni, S.; Barbero, C. A.; Rivarola, V. A.; Bertuzzi, M. L.; Yslas, E. I. Journal of Nanoscience and Nanotechnology 2016, 16, (8), 7983-7988.

33. Getzenberg, R. H.; Coffey, D. S. Molecular pharmaceutics 2011, 8, (6), 2089-2093.

34. Abel, S. B.; Yslas, E. I.; Rivarola, C. R.; Barbero, C. A. Nanotechnology 2018, 29, 125604.

35. Stejskal, J.; Sapurina, I. Pure and Applied Chemistry 2005, 77, (5), 815-826.

36. Kumar, A.; Pandey, A. K.; Singh, S. S.; Shanker, R.; Dhawan, A. Free Radical Biology and Medicine 2011, 51, (10), 1872-1881.

37. Acevedo, D. F.; Rivarola, C. R.; Miras, M. C.; Barbero, C. A. Electrochimica Acta 2011, 56, (10), 34683473.

38. Salavagione, H.; Morales, G.; Miras, M.; Barbero, C. Acta Polymerica 1999, 50, (1), 40-44.

39. Acevedo, D. F.; Miras, M. C.; Barbero, C. A. Journal of combinatorial chemistry 2005, 7, (4), 513-516.

40. Kang, E.; Neoh, K.; Tan, K. Progress in Polymer Science 1998, 23, (2), 277-324.

41. Barbero, C.; Salavagione, H. J.; Acevedo, D. F.; Grumelli, D. E.; Garay, F.; Planes, G. A.; Morales, G. M.; Miras, M. a. C. Electrochimica Acta 2004, 49, (22), 3671-3686.

42. Vijayaraghavan, P.; Liu, C. H.; Vankayala, R.; Chiang, C. S.; Hwang, K. C. Advanced Materials 2014, 26, (39), 6689-6695.

43. Hirsch, L. R.; Stafford, R. J.; Bankson, J.; Sershen, S. R.; Rivera, B.; Price, R.; Hazle, J. D.; Halas, N. J.; West, J. L. Proceedings of the National Academy of Sciences 2003, 100, (23), 13549-13554.

44. Kucekova, Z.; Kasparkova, V.; Humpolicek, P.; Sevcikova, P.; Stejskal, J. Chemical Papers 2013, 67, (8), 1103-1108.

45. Wu, C. S. Polymer International 2012, 61, (10), 1556-1563.

46. Boomi, P.; Prabu, H. G.; Mathiyarasu, J. European journal of medicinal chemistry 2014, 72, 18-25.

47. Boomi, P.; Prabu, H. G.; Manisankar, P.; Ravikumar, S. Applied Surface Science 2014, 300, 66-72.

48. Jotiram, K. P.; Prasad, R.; Jakka, V. S.; Aparna, R.; Phani, A. Nano Biomed Eng 2012, 4, (3), 144-149.

49. Hasan, J.; Crawford, R. J.; Ivanova, E. P. Trends in biotechnology 2013, 31, (5), 295-304.

50. Peng, Y.; Liu, Y.; Lu, X.; Wang, S.; Chen, M.; Huang, W.; Wu, Z.; Lu, G.; Nie, L. Journal of Materials Chemistry $B$ 2018, 6, (18), 2813-2820.

51. $\quad \mathrm{Hu}, \mathrm{Z} . ; \mathrm{Li}, \mathrm{J} . ;$ Huang, Y.; Chen, L.; Li, Z. RSC Advances 2015, 5, (1), 654-664. 


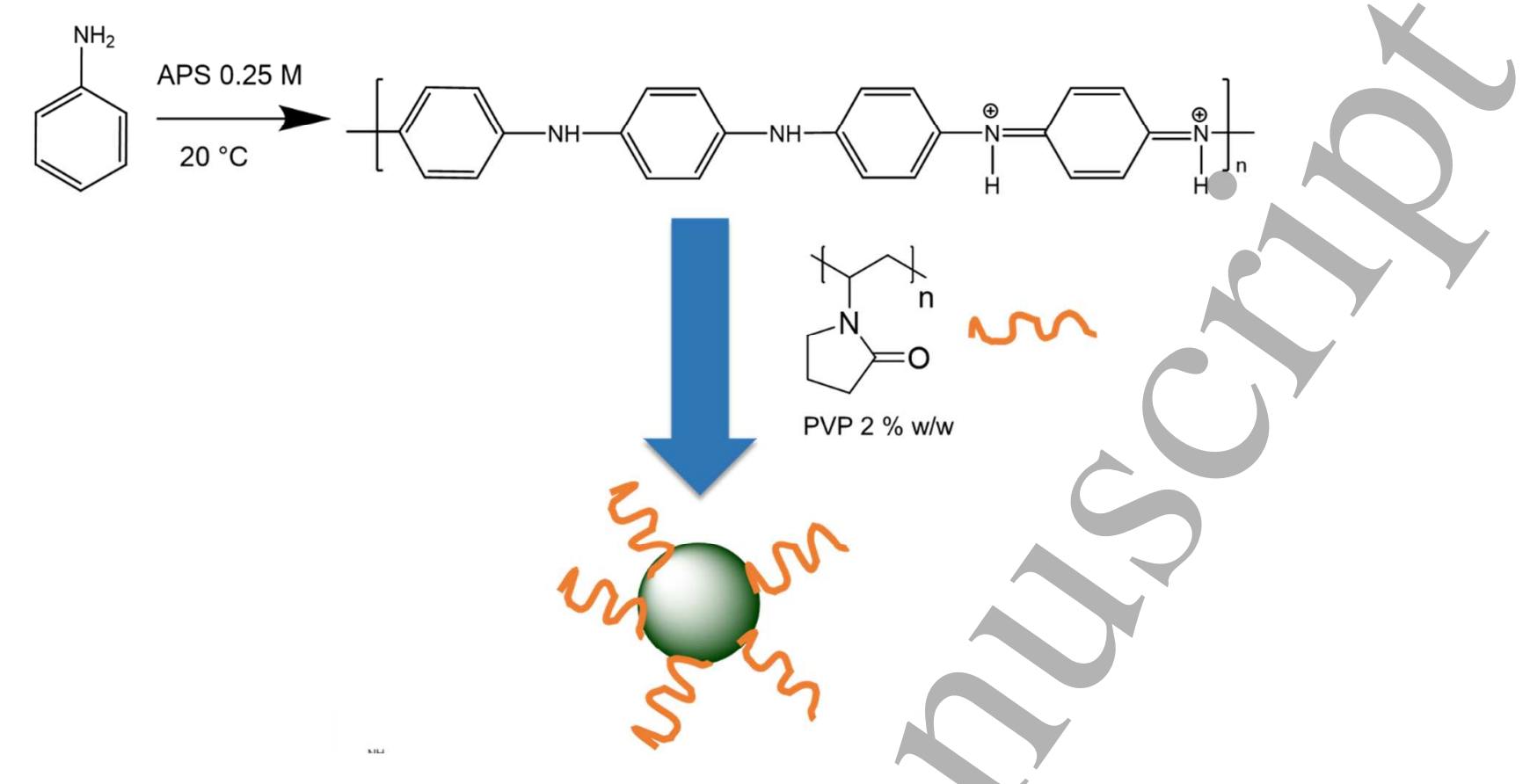

Scheme 1. Oxidative polymerization of ANI to produce PANI in the generation of PANI-NP.

Figure 1. Monomodal distribution obtained by DLS measurement of PANI-NP. Hydrodynamic diameter average (Z) and Polydispersity Index (P.D.I.) are informed. 

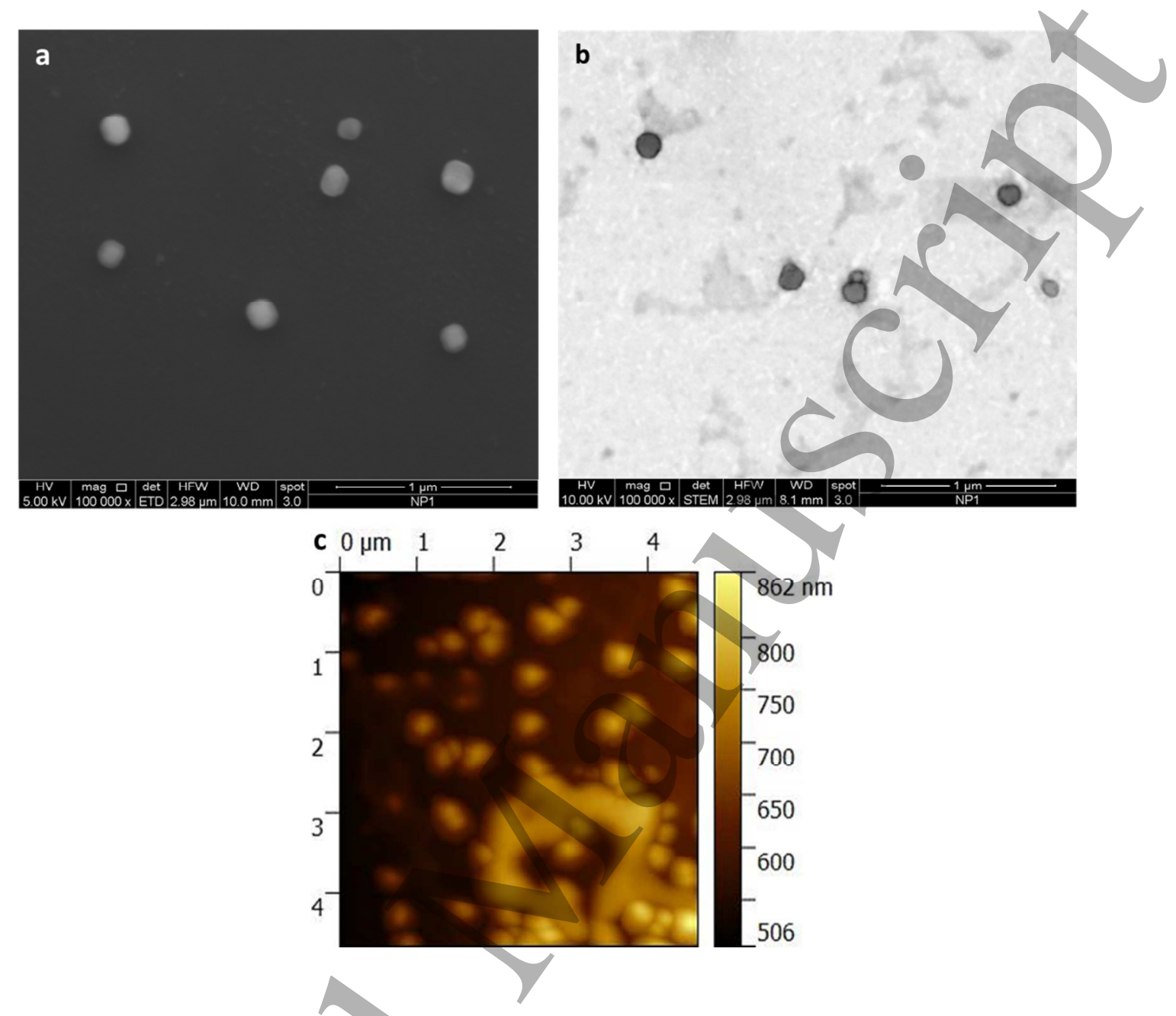

Figure. 2. a) SEM image of a dispersion of PANI-NP. Scale bar: $1 \mu \mathrm{m}$. b) TEM image of PANI-NP dispersion on copper gride. Scale bar: $1 \mu \mathrm{m} /$ and c) AFM micrograph of PANI-NP deposited on mica surface. 


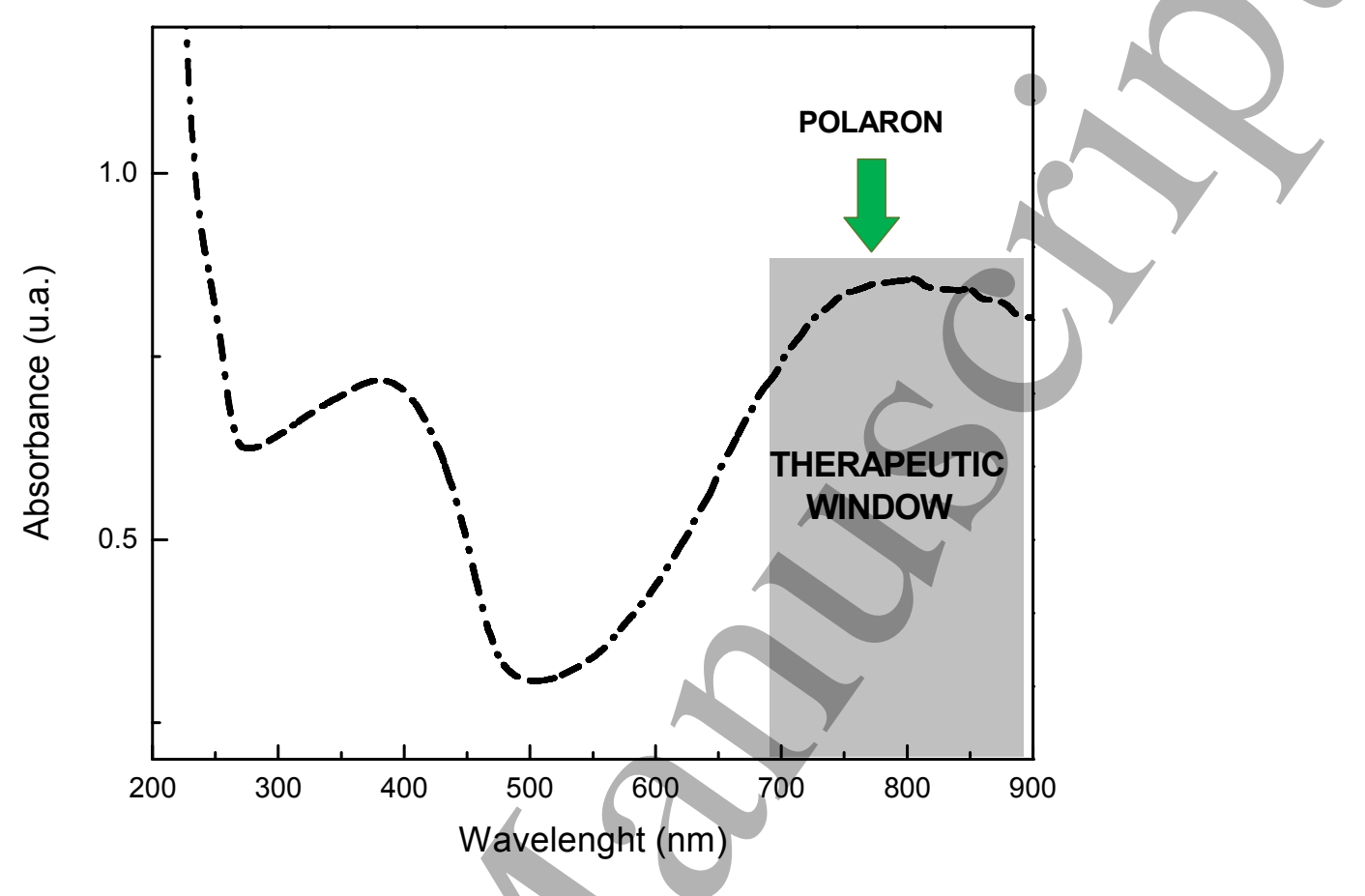

Figure 3. UV-Visible spectra of PANI-NP in acidic media. Characteristics bands of conductive polyaniline can be observed at c.a. $380 \mathrm{~nm}$ and $780 \mathrm{~nm}$ (therapeutic window). 


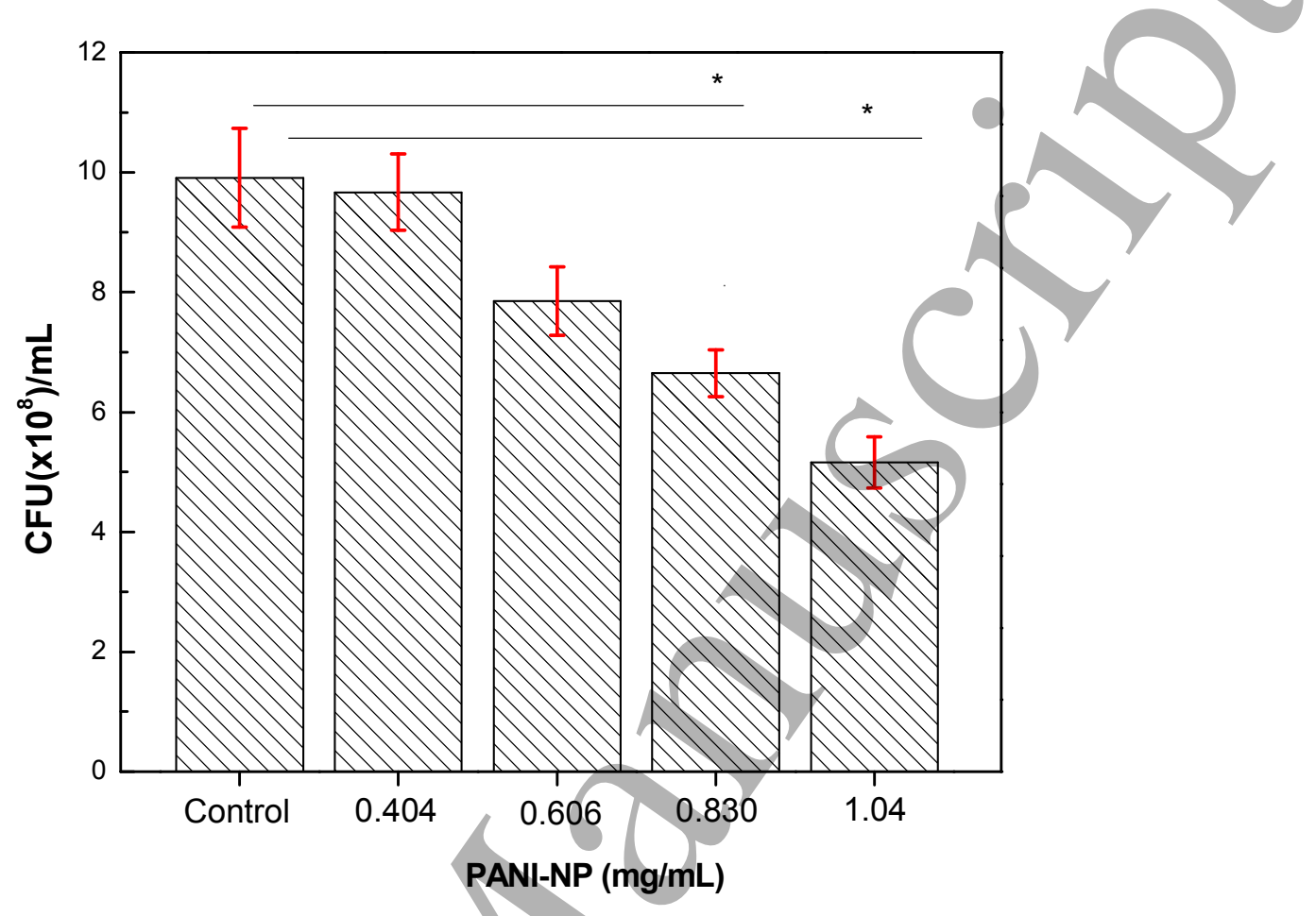

Figure 4. CFU of $P$. aeruginosa quantified by PANI-NP exposure in different concentrations $(0.404,0.606$, 0.830 and $1.04 \mathrm{mg} / \mathrm{mL}$ ) compared with the control. 


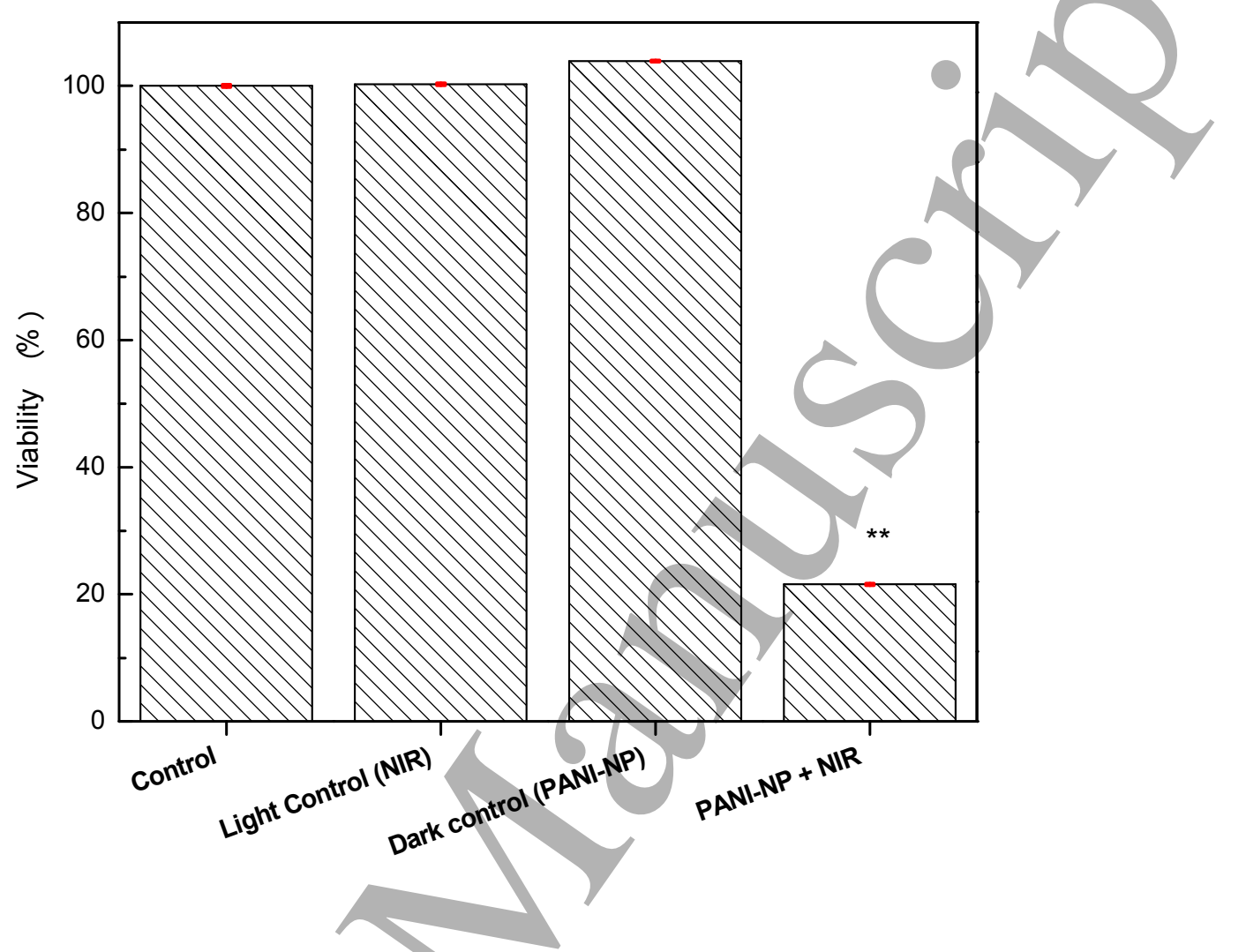

Figure 5. Viability (percentage) of $P$. aeruginosa in different conditions: control, irradiated with NIR light, exposed to PANI-NP and the combination of exposition of PANI-NP and NIR irradiation. 


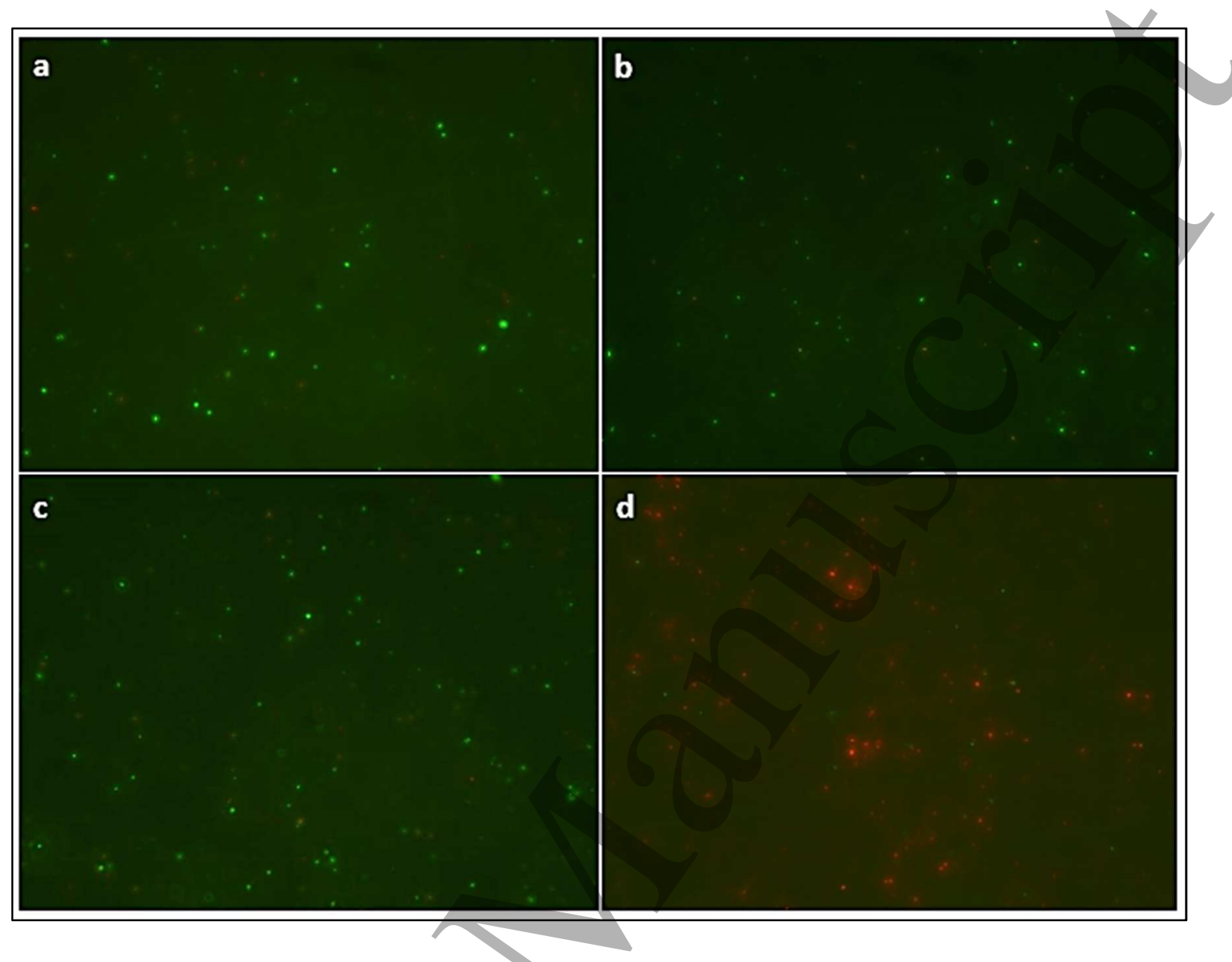

Figure 6. Fluorescence images of live and dead bacterial cells of $P$. aeruginosa with: a) control cells without PANI-NP or NIR exposure; b) cells without PANI-NP exposed to NIR; c) cells with PANI-NP, without NIR exposure; d) cells with PANI-NP and NIR exposure at wavelength of $780 \mathrm{~nm}$ of $500 \mathrm{~mW} . \mathrm{cm}^{-2}$. 
Figure 7. Agarose gel electrophoresis of DNA. Lane 1: $P$. aeruginosa (Control), lane 2: $P$. aeruginosa treatment with PANI-NP after irradiated with NIR laser (PANI-NP-NIR), lane 3: $P$. aeruginosa after treatment with PANI-NP (Dark Control), and lane 4: $P$. aeruginosa after irradiated with NIR laser (PANINP Light).

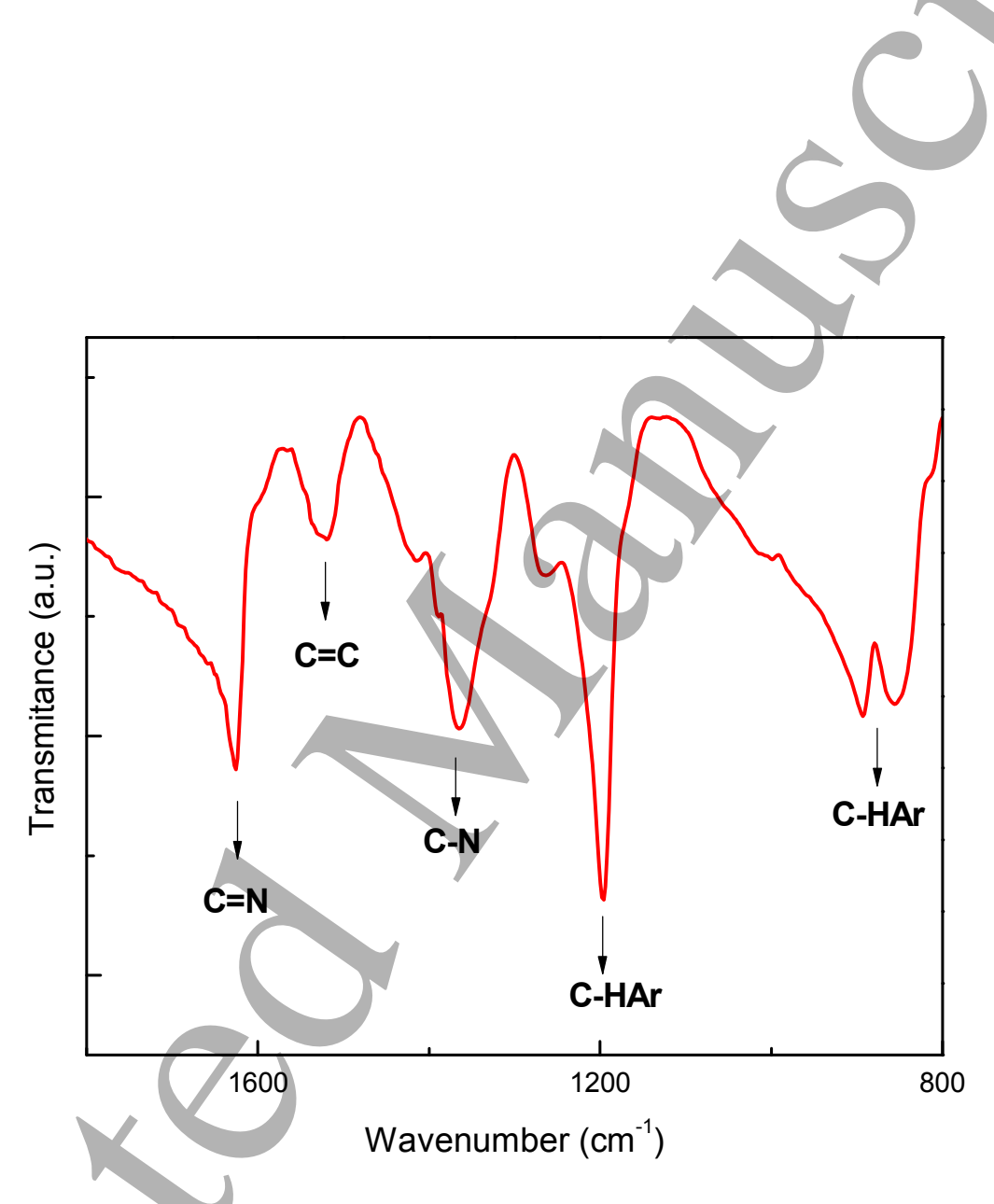

Figure 1, SI. FT-IR spectrum for PANI-NP synthesized by oxidative polymerization using PVP as stabilizer agent. Characteristics stretching and vibrations are indicated. 